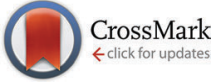

Cite this: Phys. Chem. Chem. Phys., 2016, 18, 20118

Received 29th January 2016, Accepted 31st March 2016

DOI: 10.1039/c6cp00672h

www.rsc.org/pccp

\title{
Lower temperature optimum of a smaller, fragmented triphosphorylation ribozyme $\dagger$
}

\begin{abstract}
Arvin Akoopie and Ulrich F. Müller*
The RNA world hypothesis describes a stage in the early evolution of life in which catalytic RNAs mediated the replication of RNA world organisms. One challenge to this hypothesis is that most existing ribozymes are much longer than what may be expected to originate from prebiotically plausible methods, or from the polymerization by currently existing polymerase ribozymes. We previously developed a 96-nucleotide long ribozyme, which generates a chemically activated 5'-phosphate (a 5'-triphosphate) from a prebiotically plausible molecule, trimetaphosphate, and an RNA 5'-hydroxyl group. Analogous ribozymes may have been important in the RNA world to access an energy source for the earliest life forms. Here we reduce the length of this ribozyme by fragmenting the ribozyme into multiple RNA strands, and by successively removing its longest double strand. The resulting ribozyme is composed of RNA fragments with none longer than 34 nucleotides. The temperature optimum was $\sim 20{ }^{\circ} \mathrm{C}$, compared to $\sim 40{ }^{\circ} \mathrm{C}$ for the parent ribozyme. This shift in temperature dependence may be a more general phenomenon for fragmented ribozymes, and may have helped RNA world organisms to emerge at low temperature.
\end{abstract}

\section{Introduction}

The RNA world is an early, hypothetical stage of life in which RNA polymers served as both the genome and the only genomeencoded catalyst. ${ }^{1-4}$ This RNA world hypothesis is supported by the ability to explain how an interdependent DNA-RNA-protein system could have originated from a prebiotic environment, ${ }^{4}$ by the identification of 'molecular fossils' in extant life forms, ${ }^{5-8}$ and by the in vitro selection of RNA molecules that can catalyze chemical reactions required for an RNA world. ${ }^{9,10}$ However, direct evidence of RNA world organisms may never be found because they existed more than 3.4 billion years ago, when apparently modern life forms left traces in the fossil record. ${ }^{11}$ Instead, it may be possible to test how RNA world organisms could have functioned by trying to generate RNA world organisms in the lab, from prebiotically plausible compounds. ${ }^{10,12,13}$

The length of RNAs required to sustain an RNA world organism can be an important limitation, for two reasons. First, the emergence of the first self-replicating RNA system requires that all RNAs are synthesized prebiotically, in the absence of catalytic RNAs. It is unclear how long prebiotically generated RNAs were but it is safe to assume that shorter RNAs were more abundant than longer RNAs. Many early studies on prebiotic RNA polymerization focused on the polymerization of $5^{\prime}$-imidazolide- and

Department of Chemistry \& Biochemistry, University of California, San Diego, USA. E-mail: ufmuller@ucsd.edu

$\dagger$ Electronic supplementary information (ESI) available. See DOI: 10.1039/c6cp00672h 5'-2-methylimidazolide-activated nucleoside $5^{\prime}$-phosphates ${ }^{14,15}$ on montmorillonite clay catalysts, ${ }^{16}$ which generated polymers with up to 40 nucleotides in length. However, these activated monomers are unlikely to have existed on prebiotic Earth because their synthesis requires high-energy intermediates. The same problem exists for 1-methyladenine as an activation group, which also mediated elongations up to 40 nucleotides. ${ }^{17}$ The polymerization of nucleoside $5^{\prime}$-phosphates is possible without activation groups under temperature cycling conditions in lipid matrix or concentrated salt solutions, which can generate polymers up to $\sim 100$ nucleotides. ${ }^{18,19}$ However, the products at least from the lipid-assisted synthesis are rich in abasic sites, which casts doubt on their usefulness for an RNA world organism. ${ }^{20}$ Nucleoside $2^{\prime}, 3^{\prime}$-cyclic phosphates appear prebiotically plausible, ${ }^{21}$ polymerize to more than 13 -nucleotides, ${ }^{22}$ and may be the most promising building block for prebiotically plausible RNA polymerization. ${ }^{23}$ The thermodynamic unfavorability of their polymerization in aqueous solution ${ }^{24}$ may be surmountable ${ }^{23}$ but the products also contain a mixture of $2^{\prime}, 5^{\prime}$ - and $3^{\prime}, 5^{\prime}$-phosphodiester bonds. ${ }^{25}$ The polymerization of $3^{\prime}, 5^{\prime}$-cyclic GMP, and $3^{\prime}, 5^{\prime}$-cyclic AMP leads to polymers with lengths up to 25 nucleotides. ${ }^{26,27}$ However, the prebiotic plausibility of $3^{\prime}, 5^{\prime}$-NMPs is controversial. ${ }^{26}$ It is not yet clear which of these or other chemistries could have generated an RNA world. All of the known methods show low yields for longer polymers, suggesting that the emergence of the first RNA world organism would have been more likely if shorter RNAs were sufficient to generate an RNA world organism. 
Second, for early RNA world organisms it may have been a challenge to evolve efficient RNA polymerase ribozymes. This idea is suggested by studies on in vitro selected ribozymes. A catalytic RNA that polymerizes RNA in a template-dependent fashion was generated by in vitro selection, ${ }^{28}$ and further in vitro selections yielded several improved variants. ${ }^{29-31}$ However, this ribozyme strongly favors one particular 11-nucleotide sequence such that the longest polymerization product with a functional sequence was a 24-nucleotide extension. ${ }^{30}$ These polymerase ribozyme variants are $\sim 190$ nucleotides in length, therefore this class of polymerase ribozymes is currently far from self-replication. Recently, a ribozyme was developed that mediates the polymerization of $5^{\prime}$-triphosphorylated oligonucleotides and nucleosides of the opposite stereochemistry. ${ }^{32}$ This cross-chiral approach effectively prevented product inhibition, and mediated the polymerization of an 83-nucleotide long, catalytically active RNA from NTPs and short, triphosphorylated RNA fragments. However, RNA fragments need to be polymerized themselves, and using short RNAs as substrates (instead of nucleotides) causes problems in copying fidelity. ${ }^{33}$ Therefore, even for an early RNA world organism the polymerization of long RNAs may have been a challenge. This idea suggests that not only the first instance but also the early stages of RNA world organisms would be more likely to emerge if its constituent ribozymes could assemble from short RNA polymers.

The fragmentation of ribozymes into multiple strands has been observed in nature and studied in the lab on both natural and in vitro selected ribozymes (see discussion). The present study tests the effects of fragmentation and size reduction on a triphosphorylation ribozyme - a ribozyme with importance to RNA world organisms. ${ }^{34,35}$ This ribozyme catalyzes the synthesis of chemically activated $5^{\prime}$-phosphate groups by reaction of RNA $5^{\prime}$-hydroxyl groups with the molecule trimetaphosphate (Tmp). Tmp is prebiotically plausible because it can be generated from prebiotically available phosphides via erosion and mild oxidation, and because intermediates in this pathway are also present in 3.4 billion year old marine sediments. ${ }^{36,37}$ Ribozyme-catalyzed triphosphorylation activity with Tmp is important for RNA world scenarios because it makes the free energy of Tmp hydrolysis available to RNA organisms, and the second law of thermodynamics dictates that any structure-forming entity (i.e. any life form) requires the inflow of chemical energy.

Here we show the size reduction and fragmentation of a triphosphorylation ribozyme with no RNA strand being longer than 34 nucleotides. This small and fragmented ribozyme displays reaction kinetics only 2-fold below that of the fulllength ribozyme at $22{ }^{\circ} \mathrm{C}$, and its temperature optimum is shifted from $\sim 40{ }^{\circ} \mathrm{C}$ to $\sim 20{ }^{\circ} \mathrm{C}$. The results are discussed with respect to the RNA world hypothesis.

\section{Results}

The starting construct used in this study had a length of 86 nucleotides and differed from the original isolate TPR1 ${ }^{34}$ in six mutations (Fig. 1A). These six mutations increased
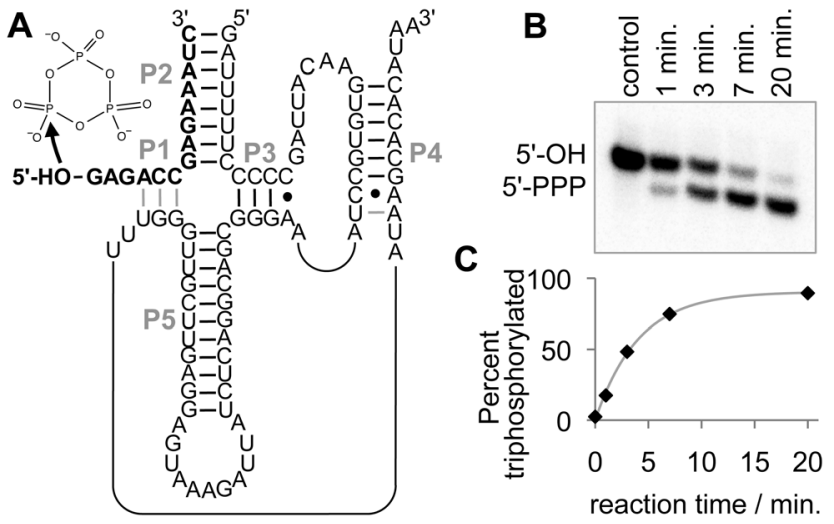

Fig. 1 The parent triphosphorylation ribozyme, its reaction, and the assay of its activity. (A) Secondary structure representation of the ribozyme. The duplexes are labeled in grey capital letters. Duplex P5 is the main focus of this study. Note that the 14-nucleotide substrate (bold) forms helices P1 and P2, and is radiolabeled internally. The nucleophilic attack of the $5^{\prime}$-hydroxyl oxygen on the trimetaphosphate is indicated with an arrow. (B) Phosphorimage of triphosphorylation products after PAGE separation. The triphosphorylated product (5'-PPP) migrates faster than the substrate $\left(5^{\prime}-\mathrm{OH}\right)$ because of the increase in negative charges. (C) Kinetics from the reaction shown in (B). The grey line is a single-exponential curve fitted to the data. All triphosphorylation data analyzed in this study were described well by single-exponential fits.

triphosphorylation kinetics 24-fold to $0.31 \mathrm{~min}^{-1}$ at $50 \mathrm{mM}$ Tmp, $100 \mathrm{mM} \mathrm{MgCl}_{2}$, and $50 \mathrm{mM}$ Tris/HCl pH 8.3; ${ }^{35}$ a seventh, slightly beneficial mutation was not included because it destabilizes the P5 stem, which is the focus of this investigation. The ribozyme binds its 14-nucleotide substrate strand via the P1 and P2 helix, and forms a pseudoknotted structure with a sum of five helices. The helix P5 contributes a large loop and an 11-base pair long double-strand to the ribozyme. To reduce the length of required RNAs we split the ribozyme at the L5 loop and successively truncated the length of the P5 helix. The intermediates of this fragmentation-and-size reduction were studied in their ability to catalyze the triphosphorylation of the $5^{\prime}$-hydroxyl group at the 14-nucleotide substrate.

When the ribozyme was split at the L5 loop the two individual fragments did not show detectable triphosphorylation activity (Fig. 2). When both fragments were combined the triphosphorylation activity of the fragmented ribozyme was within error of the full-length ribozyme. This result showed that the P5 helix can be formed in trans, leading to a fully active triphosphorylation ribozyme.

The P5 duplex was truncated in several steps (Fig. 3A). The reduction of the $\mathrm{P} 5$ stem from 11 base pairs to 7, 6, and 5 base pairs did not generate a significant effect on the kinetics or the amplitude of the triphosphorylation reaction (Fig. 3B and C). In contrast, the further reduction of the P5 helix to 4, 3, 2, 1, and 0 base pairs unexpectedly caused an increase in triphosphorylation kinetics for the constructs with two and three base pairs, faster than the cis-acting ribozyme. Interestingly, the fraction of reacting ribozyme also increased from $\sim 85 \%$ to $\sim 95 \%$ when the P5 stem contained less than 5 base pairs. This observation suggests that the formation or separation of the P5 helix presents a rate-limiting 

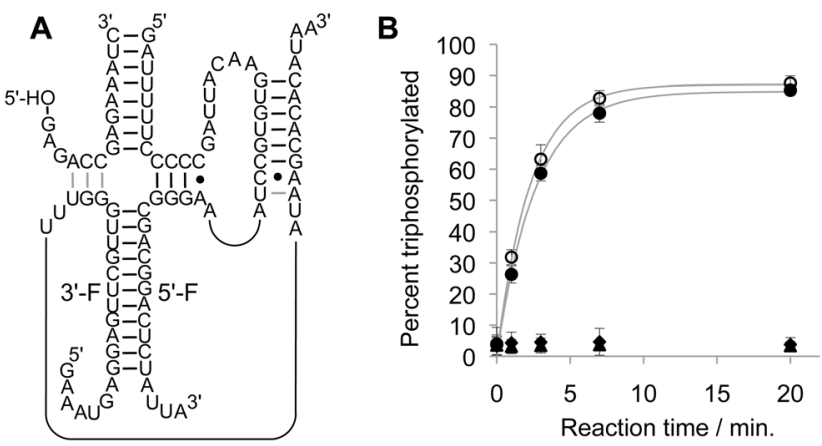

Fig. 2 Fragmentation of the ribozyme in the loop of the P5 stem. (A) Secondary structure of the fragmented ribozyme, labeling its $5^{\prime}$-fragment $\left(5^{\prime}-\mathrm{F}\right)$ and the $3^{\prime}$-fragment $\left(3^{\prime}-\mathrm{F}\right)$. (B) Reaction kinetics of the full-length, unfragmented ribozyme (empty circles), the $5^{\prime}$-fragment alone (filled triangle), the $3^{\prime}$-fragment alone (filled diamonds), and the combination of $5^{\prime}$-fragment and $3^{\prime}$-fragment (filled circles). Error bars are standard deviations from three experiments; if error bars are not visible they are smaller than the symbols.

conformational change during the triphosphorylation reaction. The shortest construct, in which the P5 helix was completely removed (Fig. 3D), showed about half of the triphosphorylation rate of the starting construct (Fig. S1, ESI $\dagger$ ). This reduction suggested that the P5 helix fulfills a function during the triphosphorylation reaction, presumably by favoring the catalytically active conformation. On the other hand, the triphosphorylation rate of $0.15 \mathrm{~min}^{-1}$ for the construct without P5 helix (as compared to $0.31 \mathrm{~min}^{-1}$ for the parental construct ${ }^{35}$ ) showed that structural elements can not only be reduced in length but also be completely omitted while maintaining a functional ribozyme.
The absence of a helix that stabilizes the catalytically active conformation would be expected to shift optimal reaction kinetics to lower temperatures. To test this idea we measured triphosphorylation kinetics at different temperatures for the full-length ribozyme (Fig. 1A) and for the trans ribozyme without the P5 duplex (Fig. 3D). Indeed, the temperature optimum of the construct without the P5 duplex $\left(15-25{ }^{\circ} \mathrm{C}\right)$ is significantly below that of the cis ribozyme $\left(40{ }^{\circ} \mathrm{C}\right)$. Two additional features of this comparison are noteworthy: first, the maximal rate of the cis ribozyme is more than two-fold above the maximal rate of the fragmented ribozyme without the P5 helix. Second, at low temperatures $\left(10{ }^{\circ} \mathrm{C}\right.$ and $\left.15{ }^{\circ} \mathrm{C}\right)$ the fragmented ribozyme without the P5 helix shows significantly faster triphosphorylation rates. This result has important implications for imagining how RNA world organisms could have functioned.

\section{Discussion}

The present study showed that an 86-nucleotide long triphosphorylation ribozyme could be fragmented in the internal duplex P5 without loss of activity, and that the P5 stem now formed in trans could be completely removed with only a 2 -fold reduction in reaction kinetics. Interestingly, intermediates in the truncation series showed triphosphorylation kinetics 2-fold faster than the parent ribozyme. The fragmented and size-reduced ribozyme showed a temperature optimum of $15-25{ }^{\circ} \mathrm{C}$ compared to $40{ }^{\circ} \mathrm{C}$ for the parent ribozyme, with faster kinetics at low temperature.

The observed advantage of the fragmented, shortest construct over the full-length ribozyme at low temperature (Fig. 4)
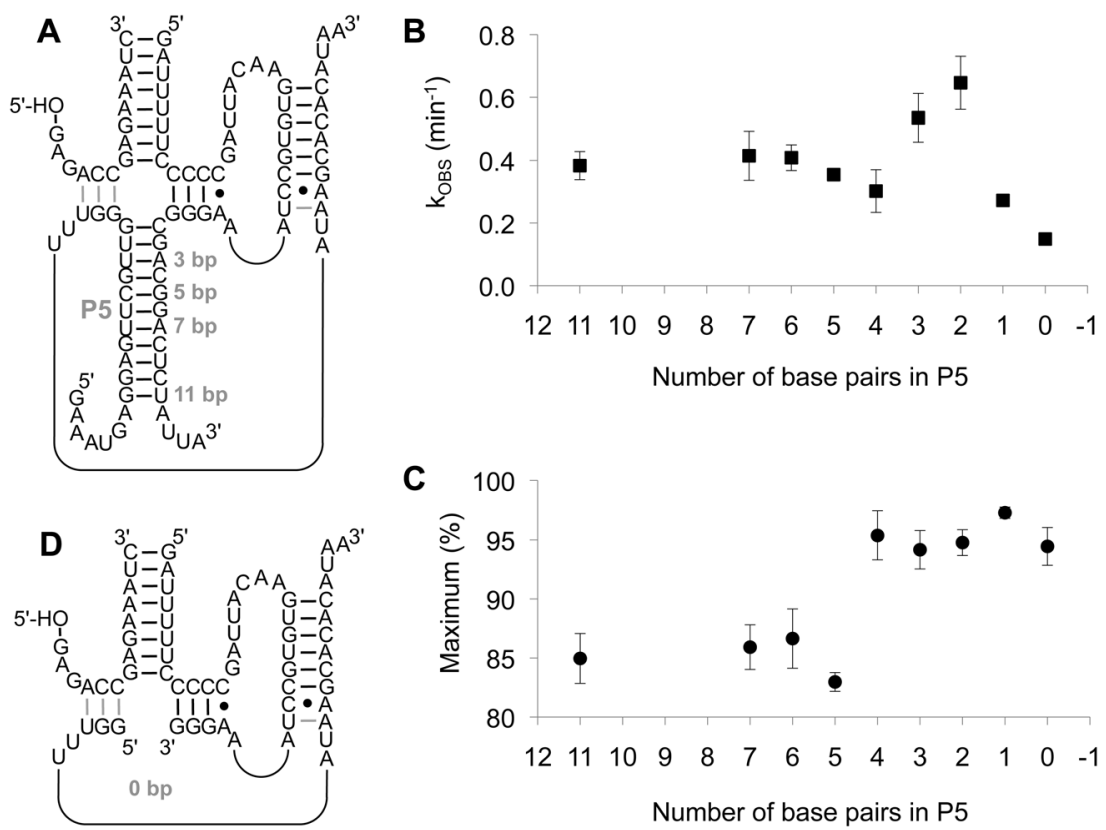

Fig. 3 Truncation of the P5 duplex in the fragmented ribozyme. (A) Secondary structure of the fragmented ribozyme. The lengths of the P5 duplex are annotated. Note that only the 11 base pair construct carried unpaired extensions that stem from the loop in the parental construct; all shorter constructs do not contain such overhangs. (B) Observed reaction kinetics with fragmented ribozyme constructs, plotted as function of their P5 duplex length. (C) Observed extent of the triphosphorylation reaction with fragmented ribozyme constructs, plotted as function of their P5 duplex length. Error bars are standard deviations from three experiments; if error bars are not visible they are smaller than the symbols. (D) Secondary structure of the shortest, fragmented ribozyme construct. The lengths of the three RNA fragments are $14 \mathrm{nt}$ (substrate), $34 \mathrm{nt}$ (5'-fragment), and $19 \mathrm{nt}$ ( $3^{\prime}$-fragment). 


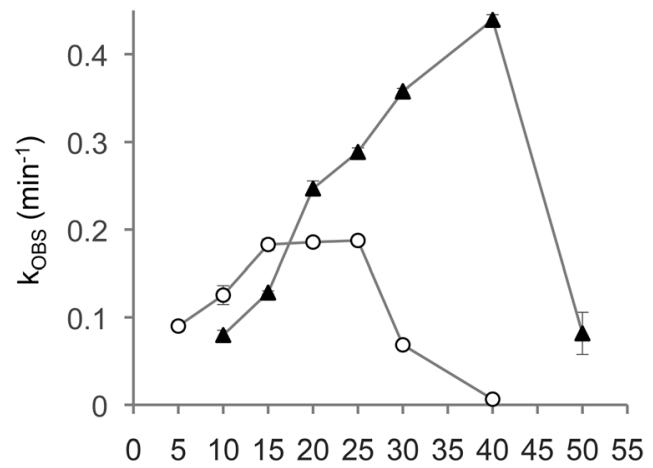

Temperature $\left({ }^{\circ} \mathrm{C}\right)$

Fig. 4 Temperature dependence of triphosphorylation kinetics. The observed reaction rates are plotted as a function of the reaction temperature for the unfragmented, full-length ribozyme (filled triangles; ribozyme sequence as shown in Fig. 1A) and the fragmented, shortest ribozyme (empty circles, ribozyme sequence as shown in Fig. 3D). Error bars are standard deviations from three experiments; if error bars are not visible they are smaller than the symbols.

may reflect a more general phenomenon. The omission of stabilizing secondary structures would allow the ribozyme structure to 'breathe' more and access the conformations required for catalysis. The temperature of the Archaean ocean appears to have been mild, probably including glaciation events (especially close to the poles), because the early Sun was $\sim 25 \%$ less bright than today. ${ }^{38-40}$ Indeed, early oceans may have been mostly frozen and only thawed episodically by meteorite impacts. ${ }^{41}$ Accordingly, the behavior of catalytic RNAs has also been explored in the lab at low temperatures, including the frozen state. A microenvironment in the eutectic spaces in ice provided the polymerase ribozyme with four key advantages: ${ }^{42,43}$ the hydrolysis of RNA and activated monomers is slowed, weak substrate interactions are improved (analogous to our finding in Fig. 4), the eutectic spaces between ice crystals afforded higher local concentrations of small molecule substrates with correspondingly faster reactions, ${ }^{44,45}$ and an isolation of eutectic spaces from each other could have provided micro-compartments to aid evolution. ${ }^{31}$ The current study suggests a fifth advantage: Low temperatures stabilize weak RNA structures including ribozymes assembled from multiple short fragments. This phenomenon would have allowed RNA world organisms to emerge and function by the assembly from short RNA fragments and therefore become more likely to occur.

The length of required RNA polymers for ribozymes can be reduced in two ways, by ribozyme fragmentation and ribozyme minimization. First, the assembly of ribozymes from multiple fragments has been seen in nature with self-splicing group I and group II introns. ${ }^{46,47}$ The group I intron from Azoarcus even lent itself to disassemble into four fragments, ${ }^{48}$ the longest of which is at least 63 nucleotides in length. ${ }^{49}$ RNase $\mathrm{P}$ can be assembled from four fragments, the longest of which is 109 nucleotides, ${ }^{50}$ the hairpin ribozyme can be separated into two structures interacting by tertiary interactions, with the longest strand being 50 nucleotides long, ${ }^{51}$ and the hammerhead ribozyme from two fragments, with the longest fragment 23 nucleotides in length. ${ }^{52}$ In vitro selected ribozymes can also assemble from multiple fragments such as variants of the DSL ribozyme, where the longest fragment is 49 nucleotides long. ${ }^{53}$ A second way to reduce the required RNA length for ribozymes is their minimization down to a catalytic core. The shortest known ribozyme is 5 nucleotides long and enhances the rate of aminoacylation by $\sim 25$-fold above the background reaction. ${ }^{54}$ Size-minimized ribozymes obtained by in vitro selections for other reactions require lengths between $31 \mathrm{nt}$ and $119 \mathrm{nt}$ in length, and typically show rate accelerations of more than a thousand-fold and often more than a million-fold. ${ }^{55-74}$ Since each of these selections sampled most of the sequence space up to 23 nucleotides these results also suggest that for most reactions, ribozymes shorter than 24 nucleotides don't exist. Because the first RNA world system would have to rely on prebiotically, nonenzymatically produced polymers these minimum lengths place a strong selection pressure for the first RNA world organism to access only the smallest ribozymes, or to assemble larger ribozymes from shorter fragments.

An additional advantage of ribozyme fragmentation lies in avoiding the inhibition of RNA polymerases by strong secondary structures. ${ }^{75,76}$ The synthesis of RNA polymers with stable secondary structures is necessary in an RNA world because most ribozymes contain strong secondary structures. In an RNA world this problem would be significant due to the difficulty of developing an RNA helicase. ${ }^{77,78}$ By separating the two partially complementary strands of a given helix onto two transcripts the helix cannot form in the transcript (or its complementary template) during synthesis, thereby avoiding the inhibition of polymerization. To our knowledge, this advantage of ribozyme fragmentation has not been published previously.

We did not expect that the complete removal of the P5 stem would lead to functional ribozymes. ${ }^{35}$ However, the fragmented ribozyme variants with truncated P5 duplex were fully functional, and two of them - with a P5 stem length of 2 and 3 base pairs were even faster than the ribozyme with a full P5 duplex (Fig. 3B). Similarly, the fraction of unreactive ribozyme was reduced from $\sim 15 \%$ for P5 lengths of 11 base pairs, to $\sim 5 \%$ for P5 lengths of 1-4 base pairs (Fig. 3C). This suggests that some flexibility at the base of the P5 stem helps to access the catalytically active conformation of the ribozyme. These observations are also consistent with the finding that ribozyme variants with a base mismatch at the second position of a full P5 helix accelerate reaction kinetics. ${ }^{35}$ Future studies with many different ribozymes may be able to determine whether this benefit of flexibility is specific for the studied ribozyme or whether it may be a general advantage of fragmented ribozymes. A general benefit for fragmented ribozymes would increase the likelihood of an RNA world emerging from a prebiotic scenario with short RNAs.

\section{Materials and methods}

Ribozyme constructs were generated by PCR mutagenesis or the Quikchange protocol for site directed mutagenesis (Stratagene). The template was a plasmid encoding the ribozyme TPR1e as described in Dolan et al. ${ }^{35}$ DNA sequences were confirmed by cloning into 
fresh pUC19 plasmids and sequencing. However, mutations near the $5^{\prime}$ - or $3^{\prime}$-termini were introduced by PCR primers during PCR amplification of the templates for transcription. RNAs were generated by run-off transcription by T7 RNA polymerase as described $^{34}$ and purified by denaturing PAGE.

The 14-nucleotide substrate was internally $\left[{ }^{32} \mathrm{P}\right]$ labeled during transcription. Two hammerhead ribozymes were encoded in the transcript, one at the $5^{\prime}$-terminus and one at the $3^{\prime}$-terminus. The $5^{\prime}$-terminal hammerhead ribozyme generated the $5^{\prime}$-hydroxyl group, while the $3^{\prime}$-terminal hammerhead ribozyme generated a homogeneous $3^{\prime}$-terminus. ${ }^{79}$ Cleaved transcripts were purified by denaturing PAGE.

Triphosphorylation reactions were performed essentially as described. ${ }^{34,35}$ Triphosphorylation reactions with $5.5 \mu \mathrm{M}$ triphosphorylation ribozyme and substoichiometric concentrations of radiolabeled substrate were incubated with $50 \mathrm{mM}$ Tmp, $100 \mathrm{mM}$ $\mathrm{MgCl}_{2}$ (corresponding to $50 \mathrm{mM}$ free $\mathrm{Mg}^{2+}$ ), and $50 \mathrm{mM}$ Tris/HCl (final pH 8.1) for three hours at $22{ }^{\circ} \mathrm{C}$ if no other temperature is given. At specific time points, $1.5 \mu \mathrm{L}$ of the reactions were added to $4 \mu \mathrm{L}$ of formamide PAGE loading buffer containing $50 \mathrm{mM}$ $\mathrm{Na}_{2}$ EDTA, heat denatured, and separated by denaturing $20 \%$ PAGE. The gel shift is caused by covalent triphosphorylation of the RNA, which was demonstrated previously by the fact that the product RNAs served as substrate for ligase ribozymes, and by mass spectrometric comparison of the RNA substrate and RNA product. ${ }^{34}$

Data quantitation: after electrophoresis, PAGE gels were exposed to phosphorimager screens and scanned on a PMI phosphorimager (Bio-Rad). Signals on the phosphorimager scans were quantitated using the software Quantity One. Curve fitting was done in Microsoft excel using single-exponential equations, minimizing the sum of the squared differences to the data using the solver sub-software.

\section{References}

1 F. H. C. Crick, The origin of the genetic code, J. Mol. Biol., 1968, 38, 367-379.

2 C. R. Woese, The fundamental nature of the genetic code: prebiotic interactions between polynucleotides and polyamino acids or their derivatives, Proc. Natl. Acad. Sci. U. S. A., 1968, 59(1), 110-117. Epub 1968/01/01. PubMed PMID: 5242115, PubMed Central PMCID: PMC286009.

3 L. E. Orgel, Evolution of the genetic apparatus, J. Mol. Biol., 1968, 38, 381-393.

4 W. Gilbert, The RNA world, Nature, 1986, 319, 618.

5 H. F. Noller, V. Hoffarth and L. Zimniak, Unusual resistance of peptidyl transferase to protein extraction procedures, Science, 1992, 256(5062), 1416-1419. Epub 1992/06/05. PubMed PMID: 1604315.

6 P. Nissen, J. Hansen, N. Ban, P. B. Moore and T. A. Steitz, The structural basis of ribosome activity in peptide bond synthesis, Science, 2000, 289(54), 920-930. Epub 2000/08/11. DOI: 8743 [pii]. PubMed PMID: 10937990.

7 H. B. White, 3rd, Coenzymes as fossils of an earlier metabolic state, J. Mol. Evol., 1976, 7(2), 101-104. PubMed PMID: 1263263.
8 G. Sprengel and H. Follmann, Evidence for the reductive pathway of deoxyribonucleotide synthesis in an archaebacterium, FEBS Lett., 1981, 132(2), 207-209.

9 X. Chen, N. Li and A. D. Ellington, Ribozyme catalysis of metabolism in the RNA world, Chem. Biodiversity, 2007, 4(4), 633-655. Epub 2007/04/20. DOI: 10.1002/cbdv.200790055. PubMed PMID: 17443876.

10 L. L. Martin, P. J. Unrau and U. F. Muller, RNA Synthesis by In Vitro Selected Ribozymes for Recreating an RNA World, Life, 2015, 5(1), 247-268. Epub 2015/01/23. DOI: life5010247 [pii]10.3390/life5010247. PubMed PMID: 25610978.

11 D. Wacey, M. R. Kilburn, M. Saunders, J. Cliff and M. D. Brasier, Microfossils of sulphur-metabolizing cells in 3.4-billionyear-old rocks of Western Australia, Nat. Geosci., 2011, 4, 698-702.

12 R. A. Sanchez and L. E. Orgel, Studies in prebiotic synthesis. V. Synthesis and photoanomerization of pyrimidine nucleosides, J. Mol. Biol., 1970, 47(3), 531-543. Epub 1970/02/14. DOI: 0022-2836(70)90320-7 [pii]. PubMed PMID: 5418170.

13 M. W. Powner, B. Gerland and J. D. Sutherland, Synthesis of activated pyrimidine ribonucleotides in prebiotically plausible conditions, Nature, 2009, 459(7244), 239-242. Epub 2009/05/16. DOI: nature08013 [pii]10.1038/nature08013. PubMed PMID: 19444213.

14 H. Sawai and L. E. Orgel, Letter: Oligonucleotide synthesis catalyzed by the Zn-2+ ion, J. Am. Chem. Soc., 1975, 97(12), 3532-3533. Epub 1975/06/11. PubMed PMID: 1141584.

15 T. Inoue and L. E. Orgel, Oligomerization of (guanosine 5'-phosphor)-2-methylimidazolide on poly(C). An RNA polymerase model, J. Mol. Biol., 1982, 162(1), 201-217. Epub 1982/11/25. DOI: 0022-2836(82)90169-3 [pii]. PubMed PMID: 6296405.

16 J. P. Ferris and G. Ertem, Oligomerization of ribonucleotides on montmorillonite: reaction of the $5^{\prime}$-phosphorimidazolide of adenosine, Science, 1992, 257(5075), 1387-1389. PubMed PMID: 1529338.

17 W. Huang and J. P. Ferris, Synthesis of 35-40 mers of RNA oligomers from unblocked monomers. A simple approach to the RNA world, Chem. Commun., 2003, 1458-1459. PubMed PMID: 12841290.

18 S. Rajamani, A. Vlassov, S. Benner, A. Coombs, F. Olasagasti and D. Deamer, Lipid-assisted synthesis of RNA-like polymers from mononucleotides, Origins Life Evol. Biospheres, 2008, 38(1), 57-74. Epub 2007/11/17. DOI: 10.1007/s11084-0079113-2. PubMed PMID: 18008180.

19 L. Da Silva, M. C. Maurel and D. Deamer, Salt-promoted synthesis of RNA-like molecules in simulated hydrothermal conditions, J. Mol. Evol., 2015, 80(2), 86-97, DOI: 10.1007/ s00239-014-9661-9. PubMed PMID: 25487518.

20 C. V. Mungi and S. Rajamani, Characterization of RNA-Like Oligomers from Lipid-Assisted Nonenzymatic Synthesis: Implications for Origin of Informational Molecules on Early Earth, Life, 2015, 5(1), 65-84, DOI: 10.3390/life5010065. PubMed PMID: 25569237, PubMed Central PMCID: PMCPMC4390841.

21 M. Renz, R. Lohrmann and L. E. Orgel, Catalysts for the polymerization of adenosine cyclic $2^{\prime}, 3^{\prime}$-phosphate on a 
poly(U) template, Biochim. Biophys. Acta, 1971, 240(4), 463-471. PubMed PMID: 4330816.

22 M. S. Verlander and L. E. Orgel, Analysis of high molecular weight material from the polymerization of adenosine cyclic 2',3'-phosphate, J. Mol. Evol., 1974, 3(2), 115-120. PubMed PMID: 4366449.

23 W. G. Scott, A. Szoke, J. Blaustein, S. M. O’Rourke and M. P. Robertson, RNA catalysis, thermodynamics and the origin of life, Life, 2014, 4(2), 131-141, DOI: 10.3390/life4020131. PubMed PMID: 25370189, PubMed Central PMCID: PMCPMC4187163.

24 S. C. Mohr and R. E. Thach, Application of ribonuclease T1 to the synthesis of oligoribonucleotides of defined base sequence, J. Biol. Chem., 1969, 244(24), 6566-6576. PubMed PMID: 4902886.

25 M. S. Verlander, R. Lohrmann and L. E. Orgel, Catalysts for the self-polymerization of adenosine cyclic $2^{\prime}, 3^{\prime}$-phosphate, J. Mol. Evol., 1973, 2(4), 303-316. Epub 1973/11/27. PubMed PMID: 4377773.

26 G. Costanzo, S. Pino, F. Ciciriello and E. Di Mauro, Generation of long RNA chains in water, J. Biol. Chem., 2009, 284(48), 33206-33216, DOI: 10.1074/jbc.M109.041905. PubMed PMID: 19801553, PubMed Central PMCID: PMCPMC2785163.

27 J. E. Sponer, J. Sponer, A. Giorgi, E. Di Mauro, S. Pino and G. Costanzo, Untemplated nonenzymatic polymerization of $3^{\prime}, 5^{\prime}$ cGMP: a plausible route to $3^{\prime}, 5^{\prime}$-linked oligonucleotides in primordia, J. Phys. Chem. B, 2015, 119(7), 2979-2989, DOI: 10.1021/acs.jpcb.5b00601. PubMed PMID: 25625780.

28 W. K. Johnston, P. J. Unrau, M. S. Lawrence, M. E. Glasner and D. P. Bartel, RNA-catalyzed RNA polymerization: accurate and general RNA-templated primer extension, Science, 2001, 292(5520), 1319-1325. PubMed PMID: 11358999.

29 H. S. Zaher and P. J. Unrau, Selection of an improved RNA polymerase ribozyme with superior extension and fidelity, RNA, 2007, 13, 1017-1026.

30 A. Wochner, J. Attwater, A. Coulson and P. Holliger, Ribozyme-catalyzed transcription of an active ribozyme, Science, 2011, 332(6026), 209-212. Epub 2011/04/09. DOI: 332/6026/209 [pii]10.1126/science.1200752. PubMed PMID: 21474753.

31 J. Attwater, A. Wochner and P. Holliger, In-ice evolution of RNA polymerase ribozyme activity, Nat. Chem., 2013, 5(12), 1011-1018. Epub 2013/11/22. DOI: nchem.1781 [pii]10.1038/ nchem.1781. PubMed PMID: 24256864, PubMed Central PMCID: PMC3920166.

32 J. T. Sczepanski and G. F. Joyce, A cross-chiral RNA polymerase ribozyme, Nature, 2014, 515(7527), 440-442. Epub 2014/11/05. DOI: nature13900 [pii]10.1038/nature13900. PubMed PMID: 25363769, PubMed Central PMCID: PMC4239201.

33 K. D. James and A. D. Ellington, The fidelity of templatedirected oligonucleotide ligation and the inevitability of polymerase function, Origins Life Evol. Biospheres, 1999, 29(4), 375-390. PubMed PMID: 10472627.

34 J. E. Moretti and U. F. Muller, A ribozyme that triphosphorylates RNA 5'-hydroxyl groups, Nucleic Acids Res., 2014, 42(7), 4767-4778. Epub 2014/01/24. DOI: gkt1405 [pii]10.1093/ nar/gkt1405. PubMed PMID: 24452796, PubMed Central PMCID: PMC3985629.
35 G. F. Dolan, A. Akoopie and U. F. Muller, A Faster Triphosphorylation Ribozyme, PLoS One, 2015, 10(11), e0142559, DOI: 10.1371/journal.pone.0142559. PubMed PMID: 26545116, PubMed Central PMCID: PMCPMC4636267.

36 M. A. Pasek, T. P. Kee, D. E. Bryant, A. A. Pavlov and J. I. Lunine, Production of potentially prebiotic condensed phosphates by phosphorus redox chemistry, Angew. Chem., Int. Ed. Engl., 2008, 47(41), 7918-7920. Epub 2008/09/11. DOI: 10.1002/anie.200802145. PubMed PMID: 18781567.

37 M. A. Pasek, J. P. Harnmeijer, R. Buick, M. Gull and Z. Atlas, Evidence for reactive reduced phosphorus species in the early Archean ocean, Proc. Natl. Acad. Sci. U. S. A., 2013, 110(25), 10089-10094. Epub 2013/06/05. DOI: 1303904110 [pii]10.1073/pnas.1303904110. PubMed PMID: 23733935, PubMed Central PMCID: PMC3690879.

38 C. Sagan and G. Mullen, Earth and Mars: evolution of atmospheres and surface temperatures, Science, 1972, 177(4043), 52-56, DOI: 10.1126/science.177.4043.52. PubMed PMID: 17756316.

39 J. D. Haqq-Misra, S. D. Domagal-Goldman, P. J. Kasting and J. F. Kasting, A revised, hazy methane greenhouse for the Archean Earth, Astrobiology, 2008, 8(6), 1127-1137, DOI: 10.1089/ast.2007.0197. PubMed PMID: 19093801.

40 J. F. Kasting, Faint young sun redox, Nature, 2010, 464, 687-689.

41 J. L. Bada, C. Bigham and S. L. Miller, Impact melting of frozen oceans on the early Earth: implications for the origin of life, Proc. Natl. Acad. Sci. U. S. A., 1994, 91, 1248-1250. PubMed PMID: 11539550, PubMed Central PMCID: PMCPMC43134.

42 P. A. Monnard and J. W. Szostak, Metal-ion catalyzed polymerization in the eutectic phase in water-ice: a possible approach to template-directed RNA polymerization, J. Inorg. Biochem., 2008, 102(5-6), 1104-1111, DOI: 10.1016/j.jinorgbio.2008.01.026. PubMed PMID: 18329104.

43 J. Attwater, A. Wochner, V. B. Pinheiro, A. Coulson and P. Holliger, Ice as a protocellular medium for RNA replication, Nat. Commun., 2010, 1(6), 76, DOI: 10.1038/ncomms76. Epub 2010/09/25. PubMed PMID: 20865803.

44 A. Kanavarioti, P. A. Monnard and D. W. Deamer, Eutectic phases in ice facilitate nonenzymatic nucleic acid synthesis, Astrobiology, 2001, 1(3), 271-281. PubMed PMID: 12448990.

45 L. Lie, S. Biliya, F. Vannberg and R. M. Wartell, Ligation of RNA Oligomers by the Schistosoma mansoni Hammerhead Ribozyme in Frozen Solution, J. Mol. Evol., 2016, 82(2-3), 81-92, DOI: 10.1007/s00239-016-9729-9. PubMed PMID: 26897022.

46 J. F. Pombert, C. Otis, M. Turmel and C. Lemieux, The mitochondrial genome of the prasinophyte Prasinoderma coloniale reveals two trans-spliced group I introns in the large subunit rRNA gene, PLoS One, 2013, 8(12), e84325. Epub 2014/01/05. DOI: 10.1371/journal.pone.0084325 PONED-13-37966 [pii]. PubMed PMID: 24386369, PubMed Central PMCID: PMC3873408.

47 M. Goldschmidt-Clermont, Y. Choquet, J. Girard-Bascou, F. Michel, M. Schirmer-Rahire and J. D. Rochaix, A small chloroplast RNA may be required for trans-splicing 
in Chlamydomonas reinhardtii, Cell, 1991, 65(1), 135-143. Epub 1991/04/05. DOI: 0092-8674(91)90415-U [pii]. PubMed PMID: 1707343.

48 E. J. Hayden and N. Lehman, Self-assembly of a group I intron from inactive oligonucleotide fragments, Chem. Biol., 2006, 13(8), 909-918. Epub 2006/08/26. DOI: S10745521(06)00224-9 [pii]10.1016/j.chembiol.2006.06.014. PubMed PMID: 16931340.

49 A. S. Burton and N. Lehman, Enhancing the prebiotic relevance of a set of covalently self-assembling, autorecombining RNAs through in vitro selection, J. Mol. Evol., 2010, 70(3), 233-241. Epub 2010/03/04. DOI: 10.1007/s00239-010-9325-3. PubMed PMID: 20198367.

50 C. Guerrier-Takada and S. Altman, Reconstitution of enzymatic activity from fragments of M1 RNA, Proc. Natl. Acad. Sci. U. S. A., 1992, 89(4), 1266-1270. PubMed PMID: 1741379, PubMed Central PMCID: PMCPMC48430.

51 S. E. Butcher, J. E. Heckman and J. M. Burke, Reconstitution of hairpin ribozyme activity following separation of functional domains, J. Biol. Chem., 1995, 270(50), 29648-29651. PubMed PMID: 8530348.

52 K. Adamala, A. E. Engelhart and J. W. Szostak, Generation of functional RNAs from inactive oligonucleotide complexes by non-enzymatic primer extension, J. Am. Chem. Soc., 2015, 137(1), 483-489, DOI: 10.1021/ja511564d. PubMed PMID: 25521912.

53 N. Isomoto, Y. Maeda, T. Tanaka, H. Furuta and Y. Ikawa, Fixation and accumulation of thermotolerant catalytic competence of a pair of ligase ribozymes through complex formation and cross ligation, J. Mol. Evol., 2013, 76(1-2), 48-58, DOI: 10.1007/s00239-012-9536-x. PubMed PMID: 23288433.

54 R. M. Turk, N. V. Chumachenko and M. Yarus, Multiple translational products from a five-nucleotide ribozyme, Proc. Natl. Acad. Sci. U. S. A., 2010, 107(10), 4585-4589, DOI: 10.1073/pnas.0912895107. PubMed PMID: 20176971, PubMed Central PMCID: PMCPMC2826339.

55 T. W. Wiegand, R. C. Janssen and B. E. Eaton, Selection of RNA amide synthases, Chem. Biol., 1997, 4, 675-683.

56 M. Wecker, D. Smith and L. Gold, In vitro selection of a novel catalytic RNA: characterization of a sulfur alkylation reaction and interaction with a small peptide, $R N A, 1996$, 2(10), 982-994. Epub 1996/10/01. PubMed PMID: 8849775, PubMed Central PMCID: PMC1369431.

57 T. J. Kang and H. Suga, In vitro selection of a 5'-purine ribonucleotide transferase ribozyme, Nucleic Acids Res., 2007, 35(12), 4186-4194. Epub 2007/06/15. DOI: gkm438 [pii] 10.1093/nar/gkm438. PubMed PMID: 17567602, PubMed Central PMCID: PMC1919479.

58 N. Niwa, Y. Yamagishi, H. Murakami and H. Suga, A flexizyme that selectively charges amino acids activated by a water-friendly leaving group, Bioorg. Med. Chem. Lett., 2009, 19(14), 3892-3894, DOI: 10.1016/j.bmcl.2009.03.114. PubMed PMID: 19364647.

59 B. Seelig and A. Jaschke, A small catalytic RNA motif with Diels-Alderase activity, Chem. Biol., 1999, 6(3), 167-176. PubMed PMID: 10074465.
60 E. A. Curtis and D. P. Bartel, New catalytic structures from an existing ribozyme, Nat. Struct. Mol. Biol., 2005, 12(11), 994-1000. PubMed PMID: 16228005.

61 H. S. Zaher, R. A. Watkins and P. J. Unrau, Two independently selected capping ribozymes share similar substrate requirements, $R N A, 2006,12(11), 1949-1958$. Epub 2006/09/ 16. DOI: rna.131306 [pii]10.1261/rna.131306. PubMed PMID: 16973893, PubMed Central PMCID: PMC1624907.

62 K. B. Chapman and J. W. Szostak, Isolation of a ribozyme with $5^{\prime}-5^{\prime}$ ligase activity, Chem. Biol., 1995, 2(5), 325-333. PubMed PMID: 9383434.

63 D. Saran, D. G. Nickens and D. H. Burke, A trans acting ribozyme that phosphorylates exogenous RNA, Biochemistry, 2005, 44(45), 15007-15016. Epub 2005/11/09. DOI: 10.1021/ bi051086h. PubMed PMID: 16274247.

64 N. Li and F. Huang, Ribozyme-catalyzed aminoacylation from CoA thioesters, Biochemistry, 2005, 44(11), 4582-4590. DOI: 10.1021/bi047576b. PubMed PMID: 15766289.

65 E. Biondi, R. R. Poudyal, J. C. Forgy, A. W. Sawyer, A. W. Maxwell and D. H. Burke, Lewis acid catalysis of phosphoryl transfer from a copper(II)-NTP complex in a kinase ribozyme, Nucleic Acids Res., 2013, 41(5), 3327-3338, DOI: 10.1093/nar/ gkt039. PubMed PMID: 23358821, PubMed Central PMCID: PMCPMC3597699.

66 M. P. Robertson and W. G. Scott, The structural basis of ribozyme-catalyzed RNA assembly, Science, 2007, 315(5818), 1549-1553, DOI: 10.1126/science.1136231. PubMed PMID: 17363667.

67 J. Rogers and G. F. Joyce, The effect of cytidine on the structure and function of an RNA ligase ribozyme, RNA, 2001, 7(3), 395-404. Epub 2001/05/03. PubMed PMID: 11333020, PubMed Central PMCID: PMC1370096.

68 S. Tsukiji, S. B. Pattnaik and H. Suga, An alcohol dehydrogenase ribozyme, Nat. Struct. Biol., 2003, 10(9), 713-717. PubMed PMID: 12910259.

69 T. P. Wang, Y. C. Su, Y. Chen, Y. M. Liou, K. L. Lin and E. C. Wang, et al., In vitro selection and characterization of a novel $\mathrm{Zn}$ (II)-dependent phosphorothiolate thiolesterase ribozyme, Biochemistry, 2012, 51(1), 496-510. Epub 2011/ 12/20. DOI: 10.1021/bi201585d. PubMed PMID: 22175782.

70 S. Baskerville and D. P. Bartel, A ribozyme that ligates RNA to protein, Proc. Natl. Acad. Sci. U. S. A., 2002, 99(14), 9154-9159. Epub 2002/06/22. DOI: 10.1073/pnas.142153799 142153799 [pii]. PubMed PMID: 12077317, PubMed Central PMCID: PMC123110.

71 E. H. Ekland and D. P. Bartel, The secondary structure and sequence optimization of an RNA ligase ribozyme, Nucleic Acids Res., 1995, 23(16), 3231-3238. PubMed PMID: 7667099.

72 S. Fusz, A. Eisenfuhr, S. G. Srivatsan, A. Heckel and M. Famulok, A ribozyme for the aldol reaction, Chem. Biol., 2005, 12(8), 941-950. PubMed PMID: 16125106.

73 A. Jenne and M. Famulok, A novel ribozyme with ester transferase activity, Chem. Biol., 1998, 5(1), 23-34.

74 K. E. Chapple, D. P. Bartel and P. J. Unrau, Combinatorial minimization and secondary structure determination of a 
nucleotide synthase ribozyme, RNA, 2003, 9(10), 1208-1220. PubMed PMID: 13130135.

75 B. Cisneros, D. Court, A. Sanchez and C. Montanez, Point mutations in a transcription terminator, lambda tI, that affect both transcription termination and RNA stability, Gene, 1996, 181(1-2), 127-133. PubMed PMID: 8973320.

76 I. Toulokhonov and R. Landick, The flap domain is required for pause RNA hairpin inhibition of catalysis by RNA polymerase and can modulate intrinsic termination, Mol. Cell, 2003, 12(5), 1125-1136. PubMed PMID: 14636572.
77 U. F. Muller, Re-creating an RNA world, Cell. Mol. Life Sci., 2006, 63(11), 1278-1293. PubMed PMID: 16649141.

78 N. Zenkin, Hypothesis: emergence of translation as a result of RNA helicase evolution, J. Mol. Evol., 2012, 74(5-6), 249-256, DOI: 10.1007/s00239-012-9503-6. PubMed PMID: 22544085.

79 S. R. Price, N. Ito, C. Oubridge, J. M. Avis and K. Nagai, Crystallization of RNA-protein complexes. I. Methods for the large-scale preparation of RNA suitable for crystallographic studies, J. Mol. Biol., 1995, 249(2), 398-408. Epub 1995/06/ 02. DOI: S0022283685703051 [pii]. PubMed PMID: 7540213. 